\title{
Formação Continuada Virtual em Educação Física nos Municípios de Porto Velho e Candeias do Jamari/RO: Desafios em Tempos de COVID-19
}

\author{
Continuous Virtual Training in Physical Education in the Municipalities of Porto \\ Velho and Candeias Do Jamari/RO: Challenges in COVID-19 Times
}

Formación Virtual Continua en Educación Física en los Municipios de Porto Velho Y Candeias Do Jamari/RO: Retos en Tiempos COVID-19

Clarice Lemos Ferreiraㄹ; Márcia Gonçalves Vieira²; Cleidimara Alves³; Alan Raniere Silva Xavier"; Célio José Borges ${ }^{5}$

\begin{abstract}
RESUMO
Esta pesquisa tem como objeto a formação continuada virtual de multiplicadores e professores, a partir da adequação do Referencial Curricular de Educação Física do Estado de Rondônia e como objetivos analisar as formações continuadas virtuais de multiplicadores e professores dos anos iniciais dos municípios de Porto Velho e Candeias do Jamari e seus desafios em tempos de Covid-19. A formação foi prevista para o início de 2020, no modo presencial, porém, com o advento da pandemia e a paralisação das atividades presenciais, foi necessária a reformulação das estratégias das ações com o apoio de tecnologia remota, utilizando plataformas e ferramentas virtuais para formação de 42 multiplicadores dos municípios de Rondônia e 230 professores de Porto Velho e Candeias do Jamari. Trata-se de pesquisa quanti-qualitativa e descritiva. Para a coleta dos dados, foram aplicados dois questionários, visando identificar as ferramentas mais adequadas às formações, bem como suas vantagens, limites e dificuldades. Espera-se que seja possível gerar contribuições às políticas públicas de formação de professores.
\end{abstract}

Palavras-chave: Formação continuada; Professores; Educação Física; Educação Remota; Covid-19.

\begin{abstract}
This research has as object at the virtual continuing education of multipliers and teachers, from the adequacy of the Curricular Reference of Physical Education of the State of Rondônia and as objectives to analyze the virtual continuing formations of multipliers and teachers from the initial years of the municipalities of Porto Velho and Candeias do Jamari and their challenges in times of Covid-19. The training was planned for the beginning of 2020, in the face-to-face mode, however, with the advent of the pandemic and the stoppage of face-to-face activities, it was necessary to reformulate the strategies of the actions with the support of remote technology, using platforms and virtual tools for the formation of 42 multipliers of the municipalities of Rondonia and 230 teachers of Porto Velho and Candeias do Jamari. This is a quantitative-qualitative and descriptive research. For data collection, two questionnaires were applied to identify the most appropriate tools for training, as well as
\end{abstract}

\footnotetext{
${ }^{1}$ Mestranda em Educação pela PPGE/UNIR (Fundação Universidade Federal de Rondônia), coordenadora Geral da Secretaria Municipal de Educação de Candeias do Jamari/RO - Brasil.

${ }^{2}$ Mestranda em Educação pela ENBER Philosophy University, Orlando/Flórida - Estados Unidos. Professora da rede municipal de Porto Velho/RO - Brasil.

${ }^{3}$ Doutora em Ciências do Movimento Humano e Professora da Secretaria Estadual de Educação de Rondônia e Secretaria Municipal de Educação de Porto Velho/RO - Brasil.

${ }^{4}$ Secretaria de Estado da Educação de Rondônia, Porto Velho/RO - Brasil.

${ }^{5}$ Professor Associado-4 do Departamento de Educação Física da Universidade Federal de Rondônia, Líder do Grupo de pesquisa - Centro de Estudos e Pesquisas do Humanismo Ikeda - CEPHIK e Vice-líder do Grupo de Pesquisa do Desenvolvimento e da Cultura Corporal - GDECC, Porto Velho/RO - Brasil.
} 
their advantages, limits and difficulties. It is expected that it will be possible to generate contributions to public policies for teacher training.

Keywords: Continuing education; Teachers; Physical Education; Remote Education; Covid-19.

\section{RESUMEN}

Esta investigación tiene como objetivo la educación continua virtual de multiplicadores y profesores, desde la adecuación de la Referencia Curricular de Educación Física del Estado de Rondônia y como objetivos analizar las virtuales formaciones continuas de multiplicadores y profesores desde los primeros años de los municipios de Porto Velho y Candeias do Jamari y sus retos en tiempos de Covid-19. La formación estaba prevista para principios de 2020, en el modo presencial, sin embargo, con la llegada de la pandemia y la parada de las actividades presenciales, era necesario reformular las estrategias de las acciones con el apoyo de la tecnología remota, utilizando plataformas y herramientas virtuales para la formación de 42 multiplicadores de los municipios de Rondônia y 230 profesores de Porto Velho y Candeias do Jamari. Se trata de una investigación cuantitativa-cualitativa y descriptiva. Para la recopilación de datos, se aplicaron dos cuestionarios para identificar las herramientas más adecuadas para la formación, así como sus ventajas, límites y dificultades. Se espera que sea posible generar contribuciones a las políticas públicas para la formación del profesorado.

Palabras clave: Educación continua; Profesores; Educación Física; Educación Remota; Covid-19.

\section{INTRODUÇÃO}

O presente artigo tem a finalidade de discutir a respeito dos processos de formação continuada virtual de professores de Educação Física dos diversos municípios do Estado de Rondônia, processo que foi sustentado por um planejamento para execução no formato presencial, porém, exigiu-se que se passasse para o modo virtual, desde que a Organização Mundial de Saúde - OMS - declarou em março de 2020 o surto internacional pela Covid-19, recomendando isolamento social a todos os países do mundo. O surto afetou todos os segmentos, não sendo diferente na educação (Neto, 2020).

As experiências nas formações realizadas remotas norteiam toda a escrita deste trabalho. Para Placco e Souza (2015), a escrita tem o poder de trazer de novo o que, devido à ação do tempo, ficou esquecido em algum lugar da memória. Conserva e aponta sentidos e sensações que, reencontrados, tornam-nos leitores de nós mesmos, mostrando quem éramos naquele tempo e lugar. Assim, buscamos narrar as experiências, em tempo de pandemia, como algo ainda não experimentado, para deixar registrado este momento tão importante da educação do estado de Rondônia.

E para atender ao problema de pesquisa, de acordo com o objeto de estudo, foi estabelecido o Objetivo Geral: Analisar o contexto da formação continuada virtual de multiplicadores e de professores dos anos iniciais dos municípios de Rondônia e seus impactos e desafios em tempos de Covid-19. E como questões de pesquisa, os seguintes Objetivos Específicos: 1. Analisar o contexto da formação continuada virtual de multiplicadores do RCRO dos municípios de Rondônia; 2. Analisar o contexto da formação continuada virtual de professores dos anos iniciais no município de Porto Velho; 3. Analisar o contexto da formação continuada virtual de professores dos anos iniciais no município de Candeias do Jamari; 4. Analisar impactos gerados no processo da formação presencial para o processo de formação online (remota); 5. Identificar no processo de formação de multiplicadores e de professores os recursos virtuais empregados, ou seja, as plataformas e ferramentas utilizadas; 6 . Identificar no processo de formação de multiplicadores e de professores as principais dificuldades encontradas; e 7. Analisar os impactos gerados pela formação virtual continuada em relação ao 
pensamento e ação dos multiplicadores e professores.

Em conformidade com o objeto de estudo e os objetivos estabelecidos, considera-se que a relevância desta pesquisa se dá em pelo menos quatro aspectos: (1) necessidade de compreensão e da descrição de como aconteceu o processo das formações; (2) necessidade do prosseguimento da formação da BNCC/RCRO no formato virtual; (3) compreensão de como se deu a reformulação do planejamento para a execução das formações e em que condições, tanto dos formadores quanto dos professores, e quais eram as perspectivas dos multiplicadores da Educação Física; (4) a expectativa quanto aos resultados das formações.

\section{CONTEXTUALIZAÇÃO DOS PROCESSOS FORMATIVOS}

As ações de formação dos professores de Educação Física de Rondônia iniciaram com a adequação do Referencial Curricular do estado, conforme a Base Nacional Comum Curricular - BNCC e com o objetivo de capacitar aproximadamente 8.500 professores e gestores de Rondônia assegurando o direito a aprendizagens e vivências a aproximadamente 220 mil estudantes.

Rondônia, desde 2013, possuía um Referencial Curricular, mas com a homologação da BNCC em 2019, os estados precisaram fazer a readequação em consonância com a BNCC e com as orientações preconizadas pelo Ministério da Educação - MEC, foi reelaborado pela equipe Pro-BNCC, em regime de colaboração SEDUC e UNDIME. Participaram professores da rede estadual e municipal representando as etapas da Educação Infantil, Ensino Fundamental, anos iniciais e anos finais.

A equipe Pro-BNCC fez capacitações, ofertadas pela equipe do MEC, que realizou 4 encontros presenciais, em Brasília e em São Paulo, com os formadores dos estados do Brasil, e encontros virtuais com professores tutores, por componentes curriculares. Com a reformulação do RCRO, passou-se a realizar o planejamento das formações, a equipe Pro-BNCC faria as formações em formato de cascateamento. Foi então realizada a primeira formação, em dezembro de 2019, na cidade de Cacoal, onde os gestores tiveram formação sobre Projeto Político Pedagógico - PPP e as professoras da Educação Infantil.

A formação realizada pela Secretaria de Educação do Estado de Rondônia -SEDUC, etapa anos finais, não foi realizada no formato cascateamento, a opção da SEDUC foi realizar a formação diretamente aos professores de cada componente curricular através da plataforma Cisco Webex Trainning (modelo de plataforma pela qual os participantes interagiam).

Conduzida pela UNDIME, o Ensino Fundamental - anos iniciais, permaneceu com o formato de cascateamento, sendo reformulado para o uso de plataformas e ferramentas tecnológicas. Essa formação ocorreu também pela plataforma Cisco Webex Meeting, e uso de ferramentas tecnológicas como Google Classroom, WhatsApp, Mentimeter, Google Drive, dentre outras ferramentas que deram suporte e dinamização as formações.

Foram formados 340 multiplicadores dos municípios de Rondônia, distribuídos em 88 professores da Educação Infantil, no final do ano de 2019. Nos anos iniciais, 200 professores multiplicadores foram formados e 52 gestores responsáveis pela reelaboração do PPP. Os professores multiplicadores formaram, aproximadamente, 8.500 professores e gestores através da formação por cascateamento de forma remota. 
As formações para professores multiplicadores tiveram as seguintes distribuições de carga horária: a Educação Infantil 40 horas de formação presencial, 6 horas de web conferências; os anos iniciais, 20 horas de web conferências e 20 horas de atividades complementares através do Google Classroom; e para os gestores 40 horas de atividades presenciais. Para a etapa formativa dos multiplicadores de seus municípios teve a seguinte distribuição: anos iniciais, que é o foco desta pesquisa, cada componente curricular resultou 40 horas de formação, totalizando assim 200 horas.

É importante salientar que, na formação de multiplicadores do componente Educação Física, tivemos a participação de 33 professores de Educação Física, 2 professores de área da Matemática e 7 professores pedagogos. Vale lembrar ainda que, nos anos iniciais, o professor pedagogo é responsável por ministrar todos os componentes curriculares.

\section{FORMAÇÃO CONTINUADA E PROFISSIONALIZAÇÃO DOCENTE: INFLUÊNCIAS NO MODO DE PENSAR E AGIR DE PROFESSORES}

Antes de falar de formação continuada e de profissionalização e suas influências no pensamento e ação de professores, há que se situar em que tempo e espaço estamos e de que tempo e lugar estamos falando. Se pensarmos no contexto histórico, podemos identificar alguns eventos que marcaram a humanidade, considerados como impactos mundiais, ou seja, crises que marcaram desde o século passado, tais como as guerras, a globalização na virada do século, e já, neste século, o grande movimento de refugiados, marcados por problemas de acidentes naturais e por conflitos em seus países, problemas ambientais de grande proporção, a pobreza extrema e agora a pandemia, eventos esses que impactaram de tal forma a ponto de ressignificar questões econômicas, sociais e, consequentemente, educacionais.

Nesse sentido, tomando por base o destaque da Revista SGI Quarterly (2015, No. 82, p. 1), a qual reflete sobre algumas perspectivas do mundo em 2030, que nos ajudam a compreender tendências que estão por vir, e que, com o acontecimento da pandemia as perspectivas de mudanças são inevitáveis.

Há o destaque de que em 2015 foi o prazo final para os Objetivos do Desenvolvimento do Milênio, que foram adotados pelos países membros da Organização das Nações Unidas (ONU), e foi também o ponto de partida para os Objetivos do Desenvolvimento Sustentável, como um novo conjunto de objetivos internacionais, com suas perspectivas focadas em 2030.

Nesse sentido, a pergunta central era - Que tipo de mundo habitaremos em 2030?, sendo apontados dois fatores principais que poderiam influenciar essa realidade futura: a intensa crise ambiental mundial e o rápido ritmo da evolução da ciência e da tecnologia, os quais significavam indicativos com perspectivas de alterar de modo significativo o mundo no que foi considerado como nos próximos 15 anos, ou seja até 2030. Os indicativos apontados em 2015 estão sendo vivenciados em 2020 com o evento da pandemia e a complexa e intensa prevalência das redes virtuais, portanto, pensando à frente, tendo como referência o tempo e o espaço de onde estamos, quais as perspectivas para os próximos 10 anos? Se pensado de modo bastante local, essa formação continuada foi um passo futurístico.

Nessa perspectiva futurística, Thomas Frey (SGI Quarterly, 2015. Número 82, p. 10-11) explica por que pensar no futuro é importante e apresenta algumas projeções, dentre elas as relacionadas à educação: Mais de $50 \%$ de todas as faculdades tradicionais entrará em colapso, abrindo caminho 
para o surgimento de uma nova indústria da educação; e que, a maior empresa de Internet do mundo estará relacionada ao negócio da educação e será uma empresa da qual ainda não ouvimos falar.

Ainda na perspectiva de Thomas Frey (ibidem) "Um futuro próximo, invariavelmente, tem preferências sobre os futuros de longo prazo... E quanto mais entendermos o futuro, mais fácil será interagir com ele". Para Imbernón (2006) "... aprender para pôr em prática uma inovação supõe um processo complexo, mas essa complexidade é superada quando a formação se adapta a realidade educativa da pessoa que aprende".

Acompanhando essa perspectiva, Imbernón (2006) ainda afirma que,

A formação assume um papel que vai além do ensino que pretende uma mera atualização científica, pedagógica e didática e se transforma na possibilidade de criar espaços de participação, reflexão e formação para que as pessoas aprendam e se adaptem para poder conviver com a mudança e com a incerteza.

Isso nos permite compreender e concordar com ele que, em uma sociedade democrática, é de fundamental importância formar o professor na e para a mudança, possibilitando o desenvolvimento de suas capacidades reflexivas que abram caminho para a autonomia profissional compartilhada, em que seja socializado e partilhado o conhecimento com o contexto no qual ele esteja inserido.

Chantraine-Demailly (1997), ainda que suas abordagens sejam cronologicamente de um tempo distante, ajuda-nos a compreender o contexto da formação continuada ainda nesse tempo e lugar onde estamos.

Sobre o modelo da formação da qual resultou a pesquisa possibilitou, compreender que, no âmbito da formação continuada, há distinções específicas que podem ser identificadas, em relação a alguns aspectos: o sentido do ato de formar, o tipo de relação pedagógica entre formador e formandos, a autonomia e legitimidade do formador, a natureza dos recursos, dos planos e dos saberes na formação e ainda a coerência com uma estratégia de mudança.

Nesse universo da formação continuada, são identificados quatro modelos, subdivididos em duas categorias, ou seja, as formais e informais, de acordo com os modos de socialização e de formação.

Os modelos em relação à forma, estão assim identificados por Chantraine-Demailly (1997): a) a forma universitária - que tem por finalidade predominante a transmissão do saber e da teoria, que professores e alunos estão em relação direta e imediata com um terceiro eixo, o saber, a ciência, a crítica ou a arte, das quais os professores são produtores diretos através da pesquisa e não apenas difusões. b) a forma escolar - o ensino é organizado previamente por uma estrutura ou poder legítimo, os professores, ou formadores devem ensinar saberes que são definidos prévia, ou exteriormente em um programa oficial, ou sejam, pelo estado ou por instâncias legítimas. A referência central da forma escolar é a escolaridade obrigatória, fundada na relação institucional que liga o ensino a uma legitimidade legal. Quanto aos outros dois modelos, c) a forma contratual, e d) a forma interativa reflexiva, por suas características não estabelecem relação com a formação realizada, foco deste estudo.

Procurando fazer uma relação entre a formação, o pensamento e a ação do professor, Borges (2011), em seus estudos, tomando como referência argumentos de Pacheco (1995) e Garcia (1997), tece algumas considerações sobre a formação como espaço próprio dos professores e ao pensamento e ação pelo viés da pesquisa, esclarecendo que, por se tratar de texto do próprio autor, alguns 
parágrafos a seguir estarão transcritos em parte ou no todo, da sua pesquisa.

Borges (2011) destaca também que falar de formação de professores não é algo simples, de "chavão", existem aspectos teóricos e posicionamentos epistemológicos, ideológicos e culturais determinantes, que precisam ser articulados com os resultados da pesquisa em relação ao que os professores manifestaram em suas respostas, sobre o pensam deles mesmos, em relação às mudanças ocorridas a partir das formações virtuais.

Se comparados o antes e o pós-formação virtual, em que medida o contato com novas tecnologias deram aos professores suportes, ou apenas adquiriram conhecimentos e elevaram suas autoestimas, para o desenvolvimento de suas práticas? Questões que poderão ser respondidas ou esclarecidas na apresentação e análise dos resultados.

Na perspectiva de Garcia (1997), avaliar o impacto real das atividades de formação de professores é uma necessidade imperiosa, porém se revela pouco frequente. Do mesmo modo, Borges (2011), destacando a perspectiva de Pacheco (1995), considera ser um desafio explorar e compreender o espaço próprio dos professores, seja no nível de seu pensamento, seja no nível de sua ação, pois sem uma motivação e o empenho dos principais segmentos do sistema escolar, qualquer projeto de reforma não passará de boa intenção administrativa, bem como não será de se surpreender que é dos professores e, principalmente da sua formação, que dependerá o sucesso ou insucesso de mudanças e/ou inovações educativas, que nem sempre são passíveis de mudança pela via administrativa.

\section{FORMAÇÃo VIRTUAL: CARACTERIZAÇÃO, CONCEITOS E CONTRIBUIÇÕES PARA A FORMAÇÃO DE PROFESSORES}

Para Moran, Masetto e Behrens (2000), na sociedade da informação, todos estamos reaprendendo a conhecer, a nos comunicar, a ensinar; reaprendendo a integrar o humano e o tecnológico, a integrar o individual, o grupal e o social. É importante conectar sempre o ensino com a vida do aluno.

Para o entendimento de plataformas e ferramentas tecnológicas fez-se necessário conceituar e entender as terminologias empregadas para a realização da formação dos professores multiplicadores, para que os mesmos pudessem, posteriormente, realizar as formações aos professores de seus municípios.

O ensino remoto ou aulas online são diferentes da modalidade EAD, pois preconizam a transmissão da aula em tempo real e a interação entre professor e aluno, ocorrem nos mesmos horários que as aulas da disciplina ocorreriam no modelo presencial. As aulas são ministradas pelos professores de suas próprias casas ou outros locais, e transmitidas ao vivo pela internet.

\subsection{As tecnologias que subsidiaram os trabalhos: Ferramentas, aplicativos e plataformas virtuais}

Fazendo um resgate histórico, as tecnologias digitais surgiram em meados do século XX, desde a Revolução Industrial, alterando bens e serviços até chegar à educação. Hoje temos máquinas que "pensam" e o ser humano cada vez mais evolui com descobertas científicas nas áreas da cognição humana. Processo esse que popularizou rapidamente o uso de ferramentas e aplicativos virtuais para realizar desde as demandas mais simples como ligar uma TV ou uma lâmpada até a algoritmos e 
inteligência artificial que executa correção de provas e atividades pedagógicas, uma seara de infinitas possibilidades. Filatro (2018, p. 52) conceitua tecnologia como:

A tecnologia é o veículo usado para comunicar informações que estão representadas em uma ou mais mídias. No campo educacional, uma definição mais simples abrange o conjunto de ferramentas ou serviços usados para apoiar o ensino e a aprendizagem, viabilizando a realização de atividades.

Aliados a essa visão e, a partir do momento que o trabalho foi direcionado para o virtual, os formadores tiveram que se apropriar de diversas ferramentas para desenvolver as formações.

\subsubsection{Plataformas virtuais}

As plataformas de reuniões virtuais são ambientes que proporcionam interações via áudio e vídeo, permitindo compartilhamento de telas e edições colaborativas de documentos, sendo em sua maioria gratuitos e se tornaram a solução para encurtamento de distâncias na relação ensino aprendizado nessa pandemia.

- Plataforma Cisco Webex; plataforma oficial de Rondônia para a implementação do RCRO través das formações continuadas oferecidas remotamente, possui uma divisão em sub plataformas que se adaptam a necessidade de execução das ações e usuários.

- Plataforma Google: a Google é a maior plataforma no meio da internet, empresa multinacional que oferece diversos serviços na internet que incluem ferramentas de busca e aplicativos para multitarefas online e offline, aplicativos da Google subsidiaram as ações formativas.

\subsubsection{Ferramentas digitais}

O uso de ferramentas digitais além de dinamizar as formações, é uma orientação da BNCC e cumprimento da competência 5 (Cultura Digital), as ferramentas digitais são recursos que permitem a utilização de tecnologia para facilitar acesso a informações e à comunicação que podem ser utilizados em multiplataformas como: celular, tablet, computador e periféricos. (Crespo et al, 2020). As ferramentas digitais aplicadas neste estudo permitiram o fomento de diversas estratégias e técnicas metodológicas e seus respectivos desdobramentos:

- Gamificação: compreende a aplicação de elementos de jogos em atividades de não jogos (Fadel et al, 2014), estratégia muito motivadora e contagiante para participantes que podem interagir via aplicativo ou computador, utilizamos o aplicativo Kahoot que pode ser utilizado para produção de Quizzes até para perguntas diretas em tempo real, proporcionando feedbacks em tempo real ou análises prévias do grupo a ser trabalhado.

- Sala de aula Invertida: visa aumentar o engajamento dos alunos e muda o panorama da relação ensino aprendizagem, a ideia central é utilizar a apropriação do conteúdo antes da aula para posterior discussão e criação de conceitos, nesse contexto utilizamos as ferramentas WhatsApp que é um aplicativo de mensagens instantâneas via celular que também proporciona troca de arquivos como imagens, texto e uma comunicação quase que em tempo real, outra ferramenta utilizada foi o aplicativo Mentimeter, que cria apresentações em tempo real promovendo feedbacks instantâneos evidenciando a participação dos alunos em todo o processo. 


\section{METODOLOGIA - MÉTODO E OS PROCEDIMENTOS DAS FORMAÇÕES E DAS COLETAS DE DADOS}

A presente pesquisa teve como público-alvo os professores envolvidos nos processos de formação do RCRO, com resultados descritivos de um estudo de campo de caráter quanti- qualitativo, que visou coletar fatos concretos. Segundo Araújo e Oliveira a pesquisa qualitativa é um estudo que (1997, p. 11):

(...) se desenvolve numa situação natural, é rico em dados descritivos, obtidos no contato direto do pesquisador com a situação estudada, enfatiza mais o processo do que o produto se preocupa em retratar a perspectiva dos participantes, tem um plano aberto e flexível e focaliza a realidade de forma complexa e contextualizada.

Para a realização da pesquisa, primeiramente, foram definidos qual seria o objeto de estudo, ou seja, explicar em que medida a formação continuada virtual influenciou no pensamento e ação dos professores.

\subsection{Os procedimentos utilizados nas formações; os desafios, as facilidades e as limitações}

Nesse processo de formação, iniciaram-se as formações da implementação do RCRO à luz da BNCC, subdivididas entre introdutórias por conter conhecimentos em comum para todos e específicas por componente curricular e/ou área de conhecimentos.

\section{FORMAÇÃO DE EDUCAÇÃO FÍSICA PRÓ BNCC/RCRO: MULTIPLICADORES ANOS INICIAIS}

Para Libâneo (2004), o termo formação continuada vem acompanhado de outro, a formação inicial. A formação inicial refere-se ao ensino de conhecimentos teóricos e práticos destinados à formação profissional, completados por estágios. A formação continuada é o prolongamento da formação inicial, visando ao aperfeiçoamento profissional teórico e prático no próprio contexto de trabalho e ao desenvolvimento de uma cultura geral mais ampla, para além do exercício profissional.

Após várias leituras, vídeos assistidos, testes das plataformas e ferramentas, a coordenação da UNDIME, responsável pela formação da etapa anos iniciais, definiu que seria utilizada na formação a plataforma do Cisco Webex. As ferramentas Google Classroom e WhatsApp todos os formadores eram obrigados a utilizar com seus professores multiplicadores, mas também cada formador poderia ainda incluir outras ferramentas durante as formações.

A formação para multiplicadores do componente Educação Física foi realizada em oito encontros virtuais, além das atividades no Google Classroom e grupo do WhatsApp, tendo a participação de 45 professores multiplicadores representando os municípios de Rondônia. É importante ressaltar que seis municípios não aceitaram participar da formação no formato remoto e se omitiram a participar.

\section{FORMAÇÃO DE EDUCAÇÃO FÍSICA PRÓ BNCC/RCRO: PORTO VELHO-RO}

Considerando um tempo inesperado, que exigiu mudanças e adequações devido a Covid-19, bem como novo formato de trabalho para a continuidade das formações propostas para o ano de 2020, como afirma Silva et al (2020): 
O aprendizado ubíquo é considerado uma evolução do processo de aprendizagem móvel (m-learning. Esses autores explicam que a aprendizagem ubíqua (u-learning) se refere aos processos mediados por uma infraestrutura computacional que permite aos usuários o aprendizado em seus próprios contextos ou situações, através de informações online ou físicas que facilitam e guiam o aprendizado.

As formações ocorreram também de forma remota, após a formação para os multiplicadores, contemplando todos os profissionais da Educação do município de Porto Velho, por componente curricular específico. Mas, como o número de cursistas era grande e repasse dos conteúdos poderia se tornar repetitivo, ocorreram reuniões de alinhamento e estudo do Referencial Curricular e o manuseio das plataformas, bem como os recursos tecnológicos necessários ao suporte formativo e o planejamento da pauta, incluindo as formações introdutórias (linha histórica da BNCC versus Currículo Territorial), que ocorreram nos dias 8 e 15 de julho de 2020.

Para o componente de Educação Física houve 70 inscrições de professores da rede municipal, 4 da rede estadual e 1 da rede privada, num total de 75 professores ao todo. No dia da formação participaram 91 profissionais, sendo que 16 destes eram técnicos da Secretaria Municipal de Educação de Porto Velho- SEMED.

Esta pesquisa foi sistematizada através de um questionário em formulário Google disponibilizado entre os dias 18 de setembro a 28 de setembro de 2020 aos participantes da formação em Porto Velho. Obtiveram-se 66 respostas, sendo 12 duplicadas, que foram subtraídas, restaram um total de 52 respostas válidas ao questionário.

O questionário foi composto por 15 perguntas, sendo 2 (duas abertas) e 4 semiabertas com a opção "outro", de modo que o participante poderia acrescentar opções que não estivessem contempladas entre as respostas sugeridas, e as demais, foram perguntas com respostas fechadas.

\section{FORMAÇÃO DE EDUCAÇÃO FÍSICA PRÓ BNCC/RCRO: Candeias do Jamari}

A formação de Candeias do Jamari aconteceu nos períodos de 3 de julho a 27 de agosto de 2020 para os anos iniciais. Nos dias 3, 4 e 5, o município ofereceu o conteúdo introdutório, que era a parte do Currículo comum a todos os componentes e nos dias 7 e 20 de agosto de 2020, com duração de 1:30h cada dia, especificamente, o componente de Educação Física.

Partindo da premissa de que Candeias do Jamari possui poucos professores específicos dos componentes, foram oferecidas formações para todos os professores pedagogos, responsáveis pela Recreação nas séries iniciais, além de alguns outros componentes, incluindo Educação Física, contendo um total de 121 professores inscritos na formação.

A SEMED, com o intuito de familiarizar o professor com a ferramenta da formação, a plataforma Cisco Webex, organizou previamente, reuniões e rodas de conversa, para que, quando houvesse a formação de fato, a plataforma não fosse o maior empecilho.

A formação do componente de Educação Física teve uma frequência diária de 89 professores, em média, e foi a primeira dos componentes, e utilizou de ferramentas como: Google Classroom, Youtube e Mentimeter.

Uma das queixas frequentes, durante a formação, foi o acesso à internet, o fato de o município estar em isolamento restritivo, havia muitas pessoas trabalhando em casa e demandando mais 
tempo. Isso causava embaraços, como a entrada na plataforma e falta de presença na formação.

A dificuldade também se dava pelo concílio com as aulas remotas que aconteciam concomitantemente à formação. O que fez a SEMED orientar aos professores que suspendessem os atendimentos remotos no horário da formação, com horário sugerido de 16 horas.

\section{PROCEDIMENTOS METODOLÓGICOS EMPREGADOS NOS PROCESSOS DE COLETA E SISTEMATIZAÇÃO DOS DADOS}

\section{a) Processo de coleta de dados dos multiplicadores}

Para a coleta de dados dos multiplicadores foi elaborado pela equipe de pesquisadores um questionário em sintonia com os objetivos da pesquisa constituído de 16 questões, das quais 15 eram de respostas fechadas e uma de resposta aberta, tendo sido na sequência inserido na plataforma no Google Forms.

Para a divulgação entre os professores formadores foi gerado um link pelo Google Forms e disponibilizado no grupo de WhatsApp dos multiplicadores. Após uma semana da disponibilização do link, observou-se que apenas 17 multiplicadores responderam o questionário. Então foi enviado o link no WhatsApp pessoal de cada professor que ainda não tinha respondido o questionário, obtendo $100 \%$ de respostas do questionário.

Na formação dos multiplicadores do componente Educação Física, participaram 45 professores sendo 37 professores de Educação Física, 7 professores formados em pedagogia e um professor formado em matemática. Todos os professores participantes da formação participaram da pesquisa, $100 \%$ dos questionários foram respondidos.

O questionário foi realizado através do formulário Google entre os dias 4 a 28 de setembro de 2020 . O questionário possui 16 perguntas, sendo 1 questão aberta e as demais com opção "outro", para que o participante pudesse acrescentar opções, caso o que ele quisesse responder, não estivesse contemplado entre as sugestões de resposta, e as demais, são perguntas com respostas fechadas.

A pergunta número 1 (um) trata-se do endereço de e-mail dos participantes, os quais não serão colocados aqui devido a confidencialidade das respostas e da identidade dos participantes.

\subsection{Processo de coleta de dados dos professores de Porto Velho e Candeias do Jamari}

Para a coleta de dados dos professores, foi elaborado previamente pela equipe de pesquisadores um questionário em sintonia com os objetivos da pesquisa constituído de 16 questões, das quais 15 eram de respostas fechadas e uma de resposta aberta, tendo sido na sequência inserido na plataforma no Google Forms.

\subsubsection{Porto Velho}

As formações continuadas dos professores do município de Porto Velho aconteceram por componente curricular. Houve 70 inscrições de professores da rede municipal, 4 da rede estadual e 1 da rede privada, num total de 75 professores ao todo. No dia da formação (20 de julho de 2020), participaram 91 profissionais, sendo que 16 destes eram da SEMED (Secretaria Municipal de Porto Velho). 
Para coletar as informações dos professores de Porto Velho, utilizou-se o Questionário Google Forms da plataforma Google, primeiramente via WhatsApp no grupo específico do componente de Educação Física, um convite para que pudessem colaborar com esta pesquisa respondendo o questionário, disponibilizado no link em anexo. Sendo que, neste primeiro momento, apenas 29 professores responderam, foi necessário reenviar o convite e o link para o contato individual de cada participante, tanto via WhatsApp, quanto por e-mail. Desta forma, obteve-se o total de 66 respostas ao questionário, que ficou disponibilizado em formulário Google Forms entre os dias 18 de setembro a 28 de setembro de 2020. Devido a pesquisa ser de forma online, foram enviadas mensagens de incentivo e pedido para colaboração com a pesquisa através de e-mail e WhatsApp em grupos e mesmo individual. Mas, das 66 respostas, houve 12 duplicadas, que subtraídas, restaram um total de 52 respostas ao questionário.

\subsubsection{Candeias do Jamari}

Para a coleta de dados dos multiplicadores foram elaboradas 16 questões, das quais 15 eram de respostas fechadas e uma de resposta aberta, tendo sido na sequência inserido na plataforma no Google Forms.

Foi utilizado o Questionário da plataforma Google, o Google Forms. A formadora/multiplicadora fez a primeira abordagem pelo Whatsapp, gerando o link pelo Google Forms e enviando para o Grupo 'Formação BNCC-RCRO', o qual havia os professores inscritos e participantes da formação. Nesse momento, 32 professores haviam respondido o questionário.

Analisando os acessos da formação pela plataforma Cisco, pudemos constatar que participaram 89 professores na formação do componente de Educação Física, sendo assim, foi feita uma segunda abordagem da mesma forma que a primeira, aumentando o quantitativo de respostas para 48 . Numa terceira abordagem, alcançaram-se os 89 professores.

A formação continuada para os professores de Candeias do Jamari, teve um total de 121 inscritos, no entanto, obtivemos 81 respostas no questionário. Devido ao fato de a pesquisa ser enviada pelo grupo de WhatsApp da formação por 3 (três) vezes, alguns pesquisados tiveram suas respostas duplicadas, e até triplicadas, excluindo 15 respostas, totalizando 66 respostas.

\section{A PESQUISA: RESULTADOS E ANÁLISE}

A seguir serão apresentados dois blocos de gráficos selecionados por opção dos pesquisadores, referente aos multiplicadores e de modo comparativos aos professores de Porto Velho e Candeias do Jamari, de acordo e na sequência das questões dos questionários que foram aplicados, indicando em cada bloco os resultados obtidos nas três pesquisas realizadas: a) com os professores multiplicadores; b) com os professores do Município de Porto Velho, juntamente com professores de Candeias do Jamari, bem como estarão acompanhados da descrição e análise de cada gráfico.

\section{a) QUESTIONÁRIO 1 - Qual o olhar dos professores multiplicadores participantes das formações?}

A seguir, estão os resultados do questionário relativos à pesquisa realizada com os professores multiplicadores de 45 municípios do Estado de Rondônia que participaram do processo de formação 
continuada virtual. Vale ressaltar que participaram da pesquisa $100 \%$ dos professores inscritos na formação.

\section{Gráfico 1}

\section{Antes da formação virtual com que frequência você utilizava a internet para as suas atividades profissionais?}

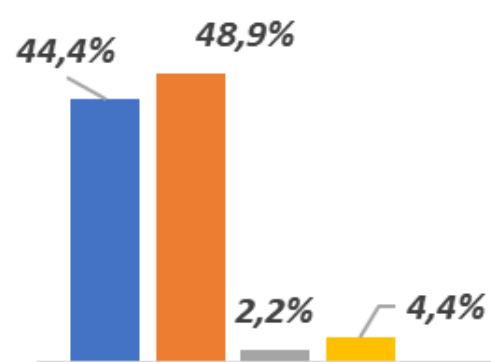

Multiplicadores

- Sempre à̀s vezes $\quad$ Nunca $\square$ Somente quando solicitado

O Gráfico 1 demonstra a frequência com que os professores utilizavam a internet para atividades profissionais, $48,9 \%$ responderam às vezes, $44,4 \%$ sempre, $4,2 \%$ quando era solicitado e $3,5 \%$ nunca.

\section{Gráfico 2}

\section{Qual dispositivo você utilizou durante a formação de multiplicadores?}

$62,2 \%$

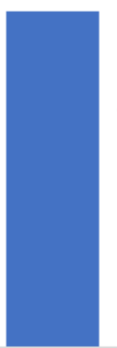

$37,8 \%$

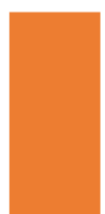

Multiplicadores

- Notebook Celular

O Gráfico 2 demonstra os dispositivos utilizados pelos multiplicadores durante sua participação na formação, 62,2\% utilizaram o notebook e $37 \%$ o celular. 
Gráfico 3

\section{Você já tinha participado de alguma formação remota antes?}

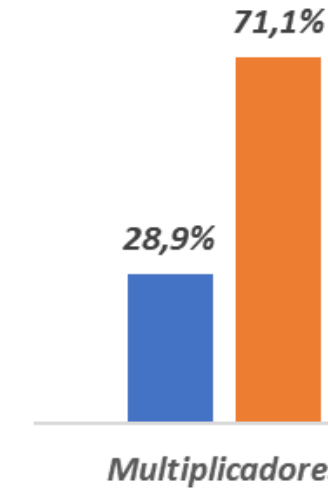

$\square \operatorname{Sim} \square$ Não

Percebe-se no Gráfico 3 que 71,1\% dos multiplicadores nunca tinham participado de nenhuma formação remota antes e apenas $28,9 \%$ dos participantes já tinham feito alguma formação remota.

Gráfico 4

\section{Qual (is) foi/foram a (as) ferramenta (as) que apresentou/apresentaram mais dificuldade (es) na sua utilização durante a formação remota.}

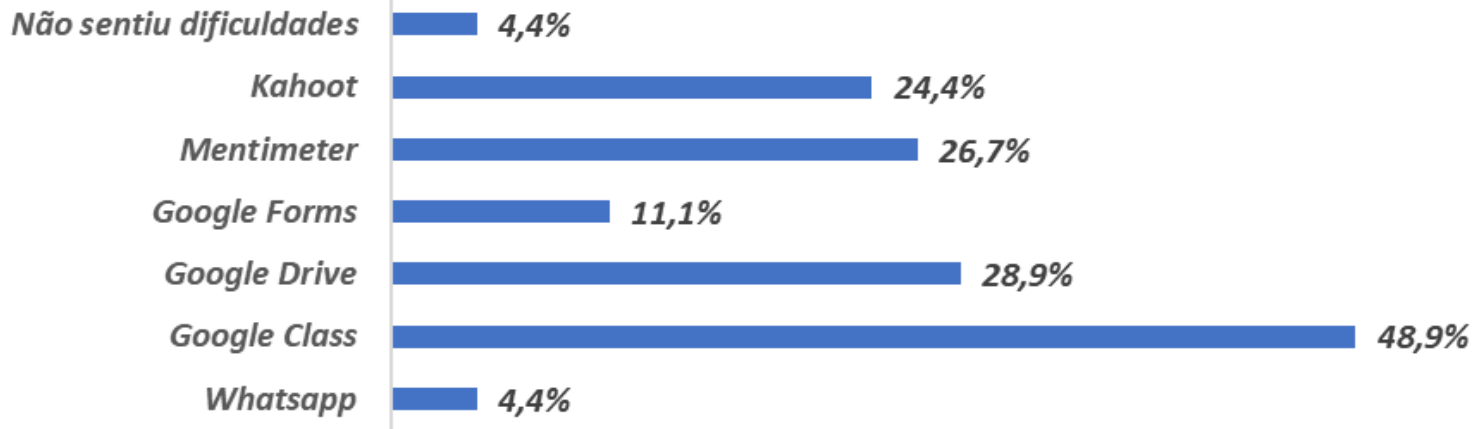

Multiplicadores

O Gráfico 4 demonstra que o Google Classroom com 48,9\%, que corresponde a 22 respostas dos multiplicadores, foi a ferramenta que mais tiveram dificuldade na utilização durante a formação remota, seguida pelo Google Drive, que obteve 13 respostas, correspondendo a 28,9\%. A ferramenta Mentimenter teve 12 respostas, que correspondem a $26,7 \%$ de multiplicadores que tiveram dificuldade na utilização da ferramenta. Já a ferramenta Kahoot que teve $24,4 \%$ que corresponde a 11 resposta dos multiplicadores também foi uma das ferramentas que mais tiveram dificuldade. 0 WhatsApp teve 4,4\% que corresponde a 2 respostas e 4,4\% responderam que não tiveram dificuldade em nenhuma das ferramentas. 


\section{Gráfico 5}

Quais os procedimentos e estratégias foram utilizadas para a formação dos professores do seu município? (Pode marcar mais de uma opção).

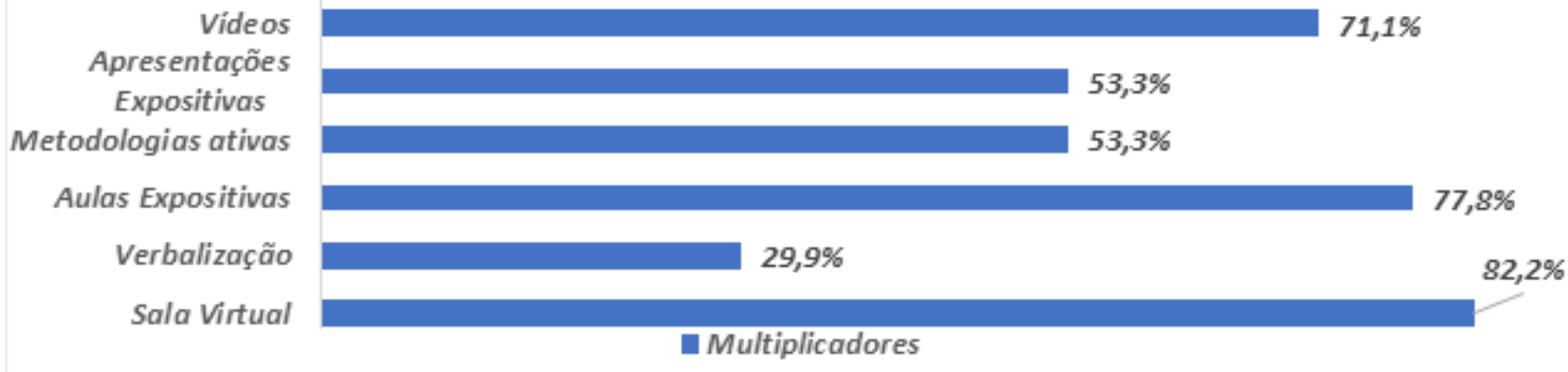

No Gráfico 5, observa se que a sala virtual foi o procedimento e estratégia mais utilizado pelos multiplicadores nas formações que os mesmos ministraram em seus municípios, seguido pelas aulas expositivas com slides, o uso de vídeos, verbalização e metodologias ativas também aparecem como os procedimentos e estratégias que foram muito utilizados pelos multiplicadores nas formações.

Gráfico 6

\section{Quais das ferramentas foram utilizadas no processo de formação dos professores do seu Município? (Pode marcar mais de uma opção).}

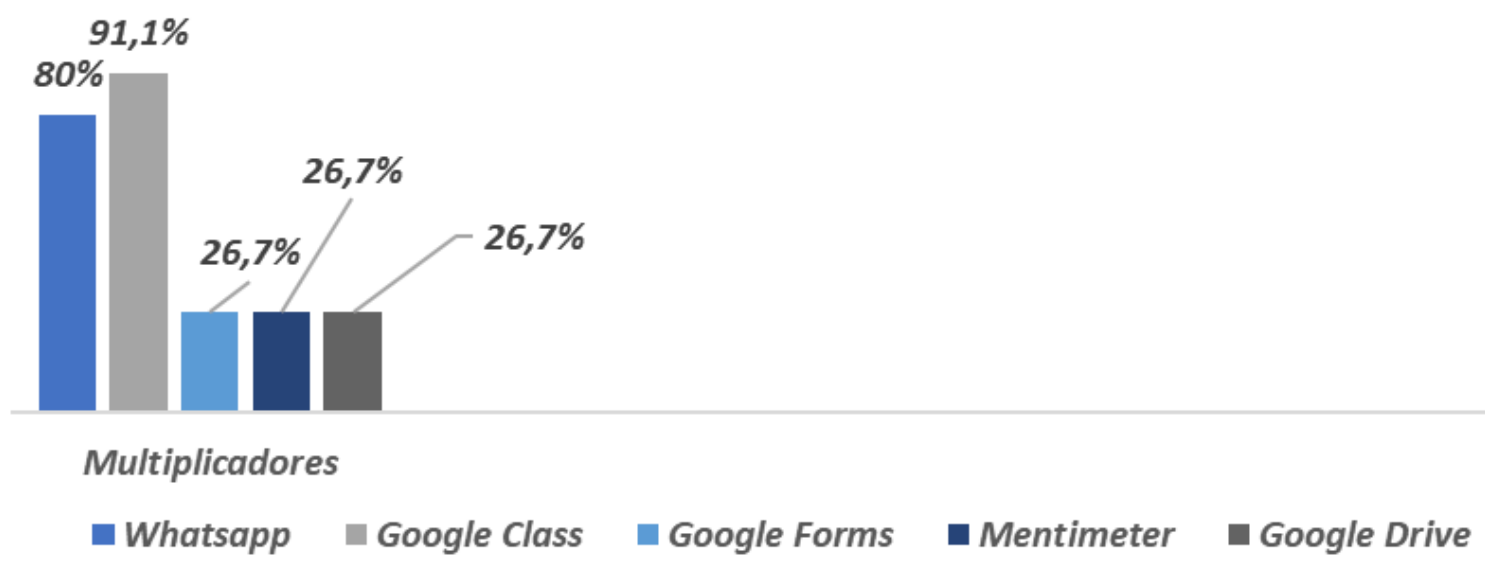

Observa se, no Gráfico 6, que a ferramenta do Google Classroom foi a mais utilizada pelos multiplicadores nas formações com 91 respostas correspondendo a $91 \%$ das ferramentas mais utilizadas nas formações seguida pelo WhatsApp com 80\% que corresponde a 36 respostas e as ferramentas Google Forms, Mentimenter e Google Drive 26,7\% cada um corresponde a 12 respostas dos multiplicadores e Webex Cisco, Kahoot e Jamboard com 2,2\% cada que corresponde a uma 
resposta por multiplicador, tendo ainda um município que não utilizou nenhuma das ferramentas por não ter realizado ainda a formação.

\section{Gráfico 7}

\section{Quais foram as dificuldades encontradas para a formação dos professores do seu município? (Pode marcar mais de uma opção)}

Falta de experiências anteriores com o ensino remoto, EAD, virtual, não presencial.

Apoio institucional aos professores participanteses

Dificuldade na interação com os professores

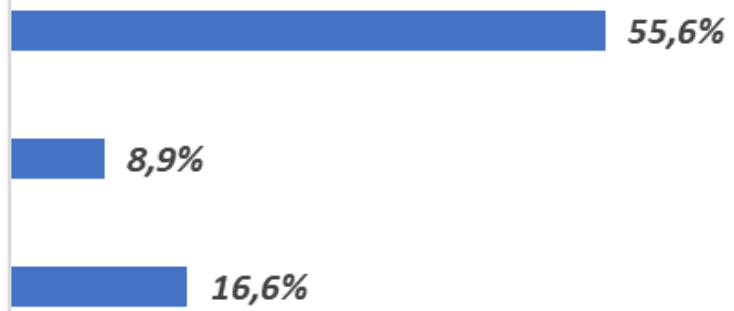

Limitações de acesso a internet

O Gráfico 7 demonstra as dificuldades dos multiplicadores para realizar as formações nos seus municípios, 34 deles, $75,6 \%$ dos participantes responderam que a limitação de acesso à internet foi a maior dificuldade encontrada, seguida pela falta de experiências anteriores com as ferramentas tecnológicas, 25 multiplicadores, $55,6 \%$ dos participantes. Dos quais 6 participantes tiveram dificuldades de interação com os professores, $15,6 \%$ das respostas e 2,2\% que corresponde a 1 resposta disse não ter realizado ainda a formação, considerou pouco tempo para a formação e resistência na participação dos professores. Esse resultado vem confirmar o gráfico 5, 60\% dos participantes dizem que a internet para a participação na formação era ruim ou péssima.

\section{b) QUESTIONÁRIO 2 - Qual o olhar dos professores participantes das formações dos municípios de Porto Velho e Candeias do Jamari (gráficos e análises correspondentes)}

A seguir serão apresentados os resultados obtidos da aplicação do questionário 2 a professores participantes do processo de formação do Município de Porto Velho e o do Município de Candeias do Jamari.

Cabe esclarecer que a pergunta número 1 (um) tratava-se do endereço de e-mail dos participantes, os quais não serão colocados aqui neste relato devido à confidencialidade das respostas e preservação da identidade dos participantes.

O questionário foi constituído de 15 perguntas, sendo 9 com respostas fechadas, 2 (duas) abertas e 4 com a opção "outro", para que o participante pudesse acrescentar opções, caso a resposta não estivesse contemplada entre as opções apresentadas. 


\section{Gráfico 8}

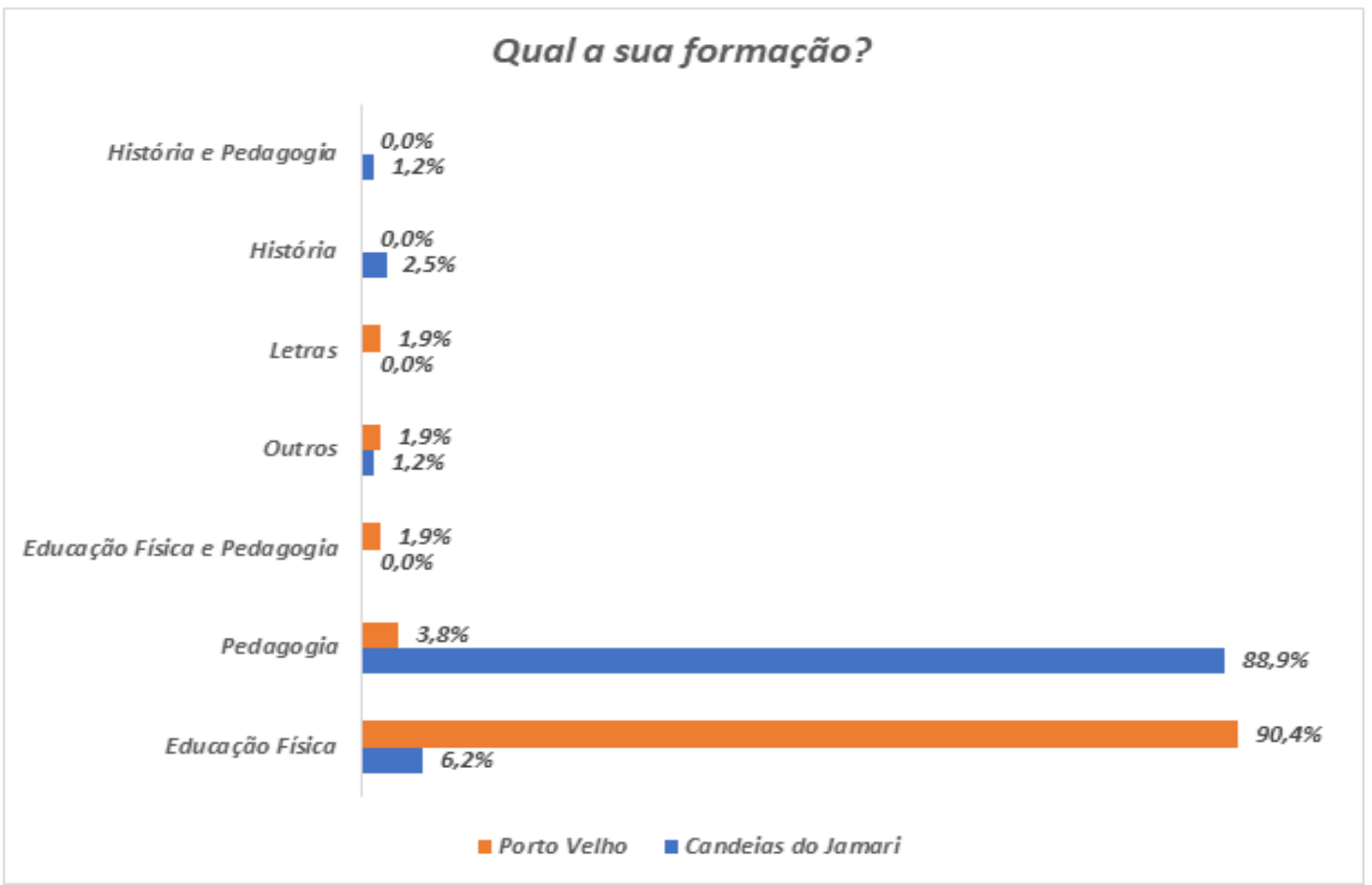

O Gráfico 8 de cada profissional, nos municípios de Porto Velho, sendo elas: $88,5 \%$ (46) no campo maior e 1,9\% (1) no campo menor, totalizando 90,4\% (47) dos professores possuem formação específica em Educação Física, 3,8\% em Pedagogia (2), 1,9\% em Educação Física e Pedagogia (1), $1,9 \%$ Normal Superior (1) e 1,9\% em Letras (1). Mostra também a formação (graduação) dos professores que participaram da pesquisa, em Candeias do Jamari, sendo elas: Educação Física (5 professores), 5,6\% respostas; Pedagogia (72 professores), 88,9\% das respostas; História (2 professores), 2,5\% das respostas; um professor respondeu que possui duas graduações, Pedagogia e História 1,2\% das respostas. Um professor respondeu "Outros", que representa 1,2\%, e a resposta dá-se devido ao quadro de professores de Candeias do Jamari ainda possuir professores com o extinto Magistério.

\section{Gráfico 9}

\section{Antes da formação Virtual,com que frequência você utilizava a internet para as suas atividades profissionais?}

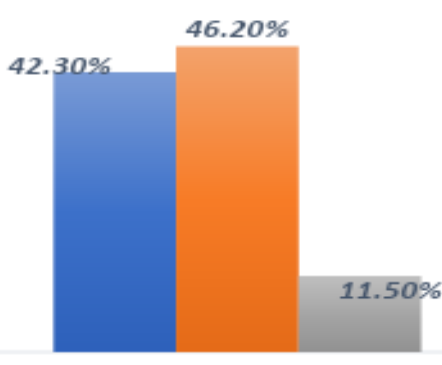

Porto Velho

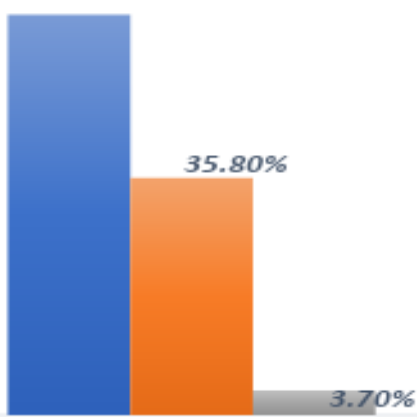

Candeias 
De acordo com o Gráfico 9, a maioria dos professores participantes de Porto Velho 46,2\% (24), utilizava a internet às vezes nas atividades profissionais. E, 42,3 \% (22) afirmam que sempre e 11,5\% utilizavam, quando solicitado (6). Já no município de Candeias do Jamari, 60,5\% (49 professores) responderam que usavam sempre, e 35,8\% (29 professores) às vezes, e 3,7\% (3 professores), somente quando eram solicitados.

Os dados aqui obtidos se tornam relevantes em termos percentuais se comparados com os dados dos multiplicadores e dos professores de Porto Velho, podemos assim supor que essa disparidade, acontece devido à implantação de internet banda larga, nas escolas de Candeias do Jamari, inclusive, na Zona Rural, às quais o acesso é disponível e ilimitado para os professores da rede através do programa federal "Educação Conectada".

\section{Gráfico 10}

De qual dispositivo você acessou a formação?

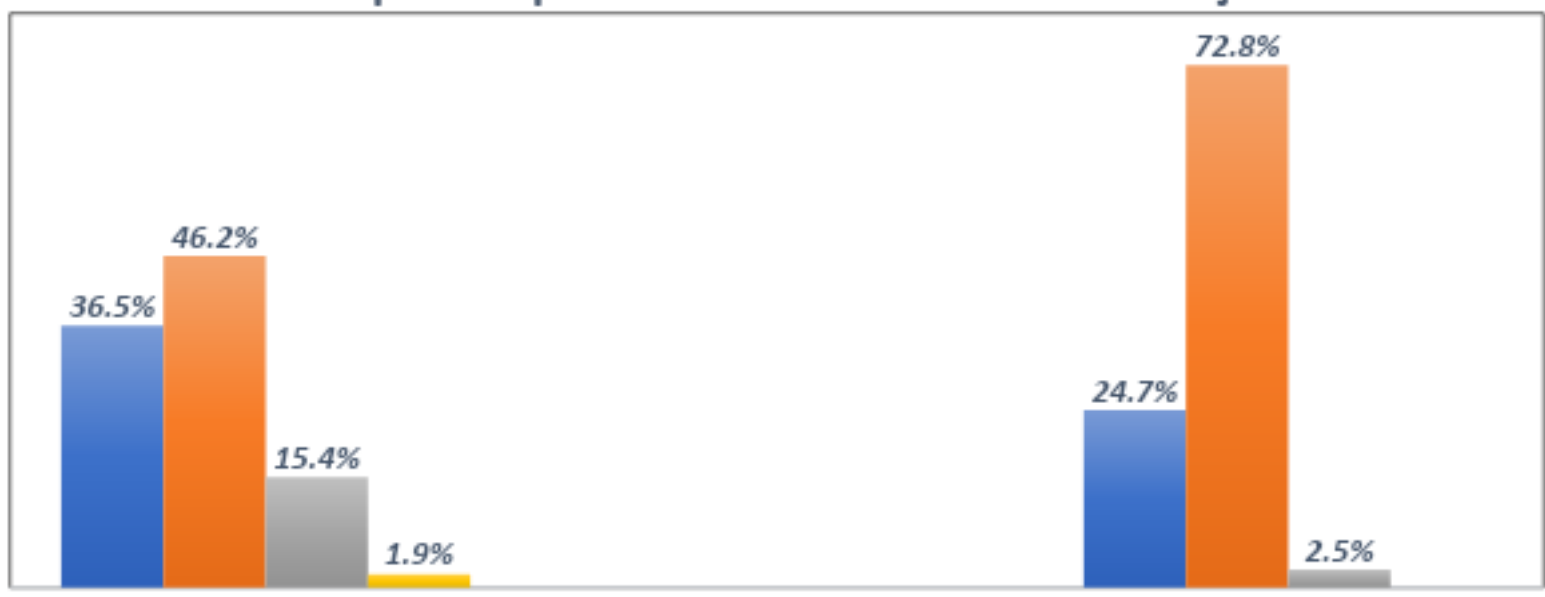

Porto Velho

Candeias

Eotebook Celular E Computador de Mesa

Estes dados do Gráfico 10 retratam as possibilidades estruturais viáveis, seja financeira e/ou praticidade, sendo que em Porto Velho, a maioria, 46,2\% (24), utilizava seus celulares, 36,5\% notebooks (19), 15,4\% computador de mesa (8) e 1,9\% tablete (1). Já, em Candeias do Jamari, indica que os dispositivos mais utilizados pelos professores respondentes durante a formação, foi expressiva, $72.7 \%$ (59) usaram o celular, 24,7\% (20) usaram Notebook, e 2,5\% (2), o computador de mesa.

Verifica-se que a utilização dos celulares predominou entre os professores pesquisados. No entanto, entre os multiplicadores foi o Notebook o mais utilizado, ou seja, pelos professores de Porto Velho, o uso do celular chegou a $50 \%$ e em Candeias do Jamari acima de $70 \%$.

O Gráfico 11 traz informações que permitem associar com o tema desta pesquisa, pois o período da formação foi no auge da quarentena em virtude da pandemia da Covid-19, demonstrando que no município de Porto Velho 96,2\% dos professores participaram de suas residências (50), ou seja, sugerem que os professores estavam em isolamento social, 1,9\% do trabalho (1) e 1,9\% de outro local não identificado (1). Em Candeias do Jamari, 95,1\% (77), indicaram ter acessado de casa e $4,9 \%(4)$, acessaram do trabalho. 
Gráfico 11

\section{Local de Acesso a Formação}

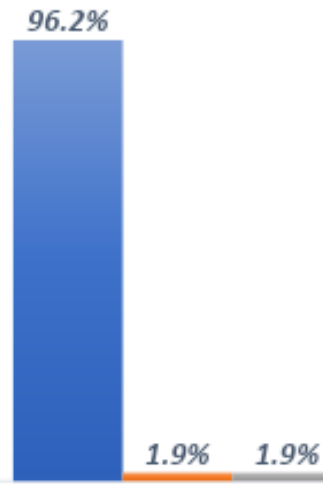

Porto Velho

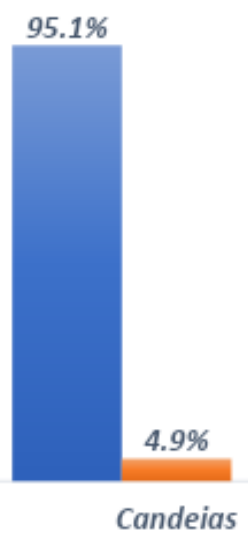

Candeias

Easa $\mathbf{E}$ Trabalho $\mathbf{O}$ Outros

Se o tema da pesquisa está relacionado com "desafios em tempo de COVID-19", esses dados são importantes, considerando que havia de modo concomitante dois processos de formação o dos professores e desses para seus alunos nas escolas, o que vem se tornar ainda mais expressivo o uso da internet para esse fim. Nesse sentido, pode considerar o gráfico relevante. Se comparados os dados com os dos multiplicadores e dos professores de Candeias do Jamari, respectivamente, $80 \%$ e $95 \%$ dos professores participaram das formações acessando a internet de suas casas.

\section{Gráfico 12}

\section{O Acesso à internet para a formação era:}

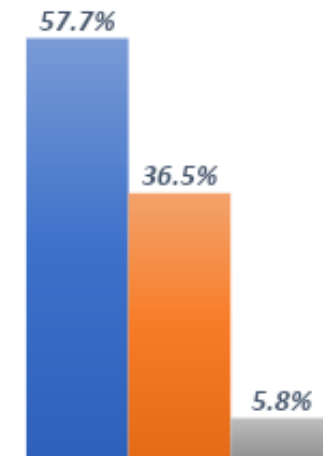

Porto Velho

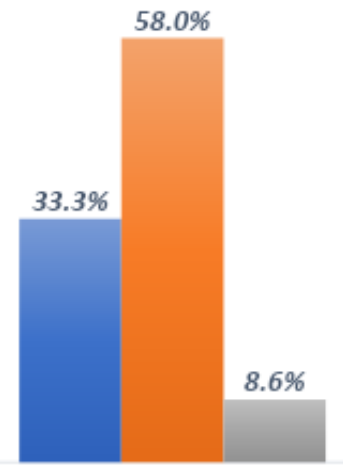

Candeias do Jamari

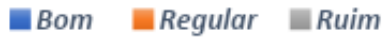

Este Gráfico 12 mostra que em Porto Velho, por ser de rede Wifi, 57,7\% consideraram a qualidade boa (30), mas dependendo do bairro e do clima diário, ocorriam também oscilações nos sinais, por isso $36,5 \%$ consideraram regular (19) e 5,8\% (3) ruim mesmo. O que confirma os dados do gráfico anterior, pois o trabalho remoto depende totalmente da internet e se esta não for de boa qualidade, interfere na comunicação entre os professores e os alunos. Já em Candeias do Jamari, tomando como referência os resultados obtidos e a vivência do processo formativo dos professores é possível afirmar que a qualidade de acesso à internet (Conexão) era uma constante durante a formação. Dentre os 
professores pesquisados, $58 \%$ (47) responderam que a qualidade do acesso era regular, 33,3\% (27), que era bom, e $8,6 \%$ (7), que era ruim.

\section{Gráfico 13}

\section{Você já tinha participado de alguma formação remota antes?}

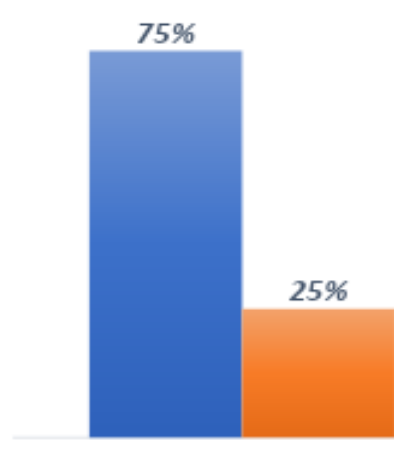

Porto Velho

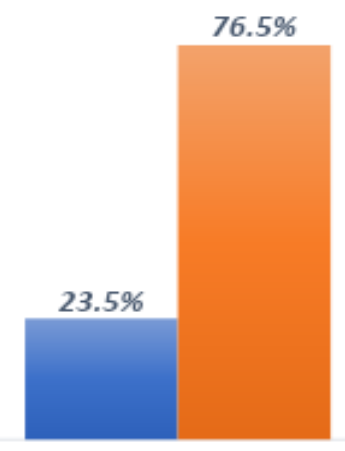

Candeias

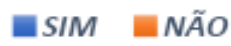

No Gráfico 13, verifica-se que em Porto Velho $75 \%$ dos professores já participaram de alguma formação remota (39), certamente pelo fato de haver formações oferecidas pela Divisão de Formação/SEMED de modo híbrido, com aulas presenciais e remotas, o que justifica a facilidade de adaptação ao novo contexto social, 25\% (13) não haviam participado.

Em relação à participação dos professores, nas formações remotas no município de Candeias do Jamari, antes da formação da BNCC/RCRO, foi constatado que 76,5\% (62) responderam que não participaram e 23,5\% (19), responderam sim, já participaram de alguma formação remota. Demonstrando que por ter um pequeno quantitativo de professores em seu quadro, há certa viabilidade em se fazer a formação presencial, além de não poder contar com estruturas.

\section{Gráfico 14}

Qual(is) da (s) Plataformas utilizadas na formação, você já tinha utilizado antes?

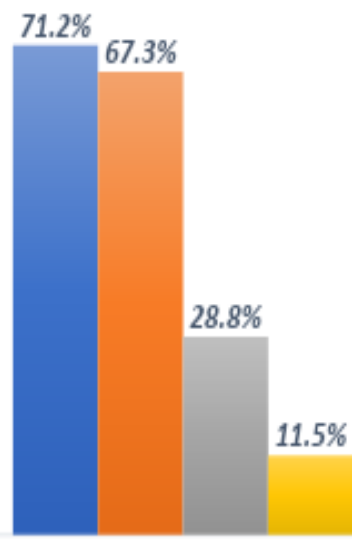

Porto Velho

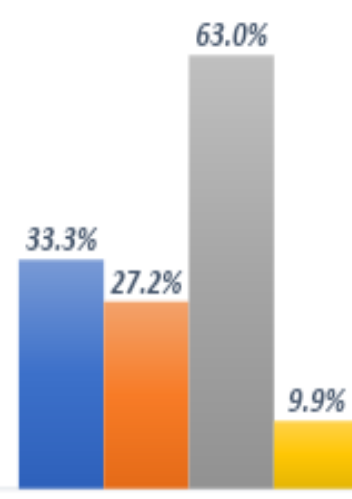

Candeias 
O Gráfico 14 acima mostra que em Porto Velho as plataformas mais utilizadas nas formações remotas pelos professores foram 71,2\% Youtube (37), escolha feita pela DIFOR/SEMED, 67,3\% Google Meet (35), 28,8\% Cisco Webex (15), esta plataforma segue as mesmas características do Google Meet, com o diferencial de poder contemplar maior número de pessoas, ressaltando que foi por meio dessa última que ocorreu a formação do Componente de Educação Física tanto como multiplicadora como formadora, $11,5 \%$ Hangouts (6).

Em Candeias do Jamari foi indagado qual plataforma (dentre as usadas na formação) os pesquisados tiveram acesso antes da formação remota BNCC/RCRO, e 63\%(51) responderam Cisco Webex, 33,3\% (27) Youtube; 27,2\%(22) Google Meet; 9,9\%(8) Hangouts; e 5\% (4) usaram outros, entre eles Zoom e Sympla.

\section{Gráfico 15}

\section{Qual(is) foi/foram a (as) ferramenta (as) que apresentou/ apresentaram mais dificuldade (es) na sua utilização durante a formação remota?}

\begin{tabular}{c|ccc|c|c|} 
Candeias do & $13,9 \%$ & $59,5 \%$ & $16,5 \%$ & $8,9 \%$ & $13,9 \%$ \\
\hline
\end{tabular}

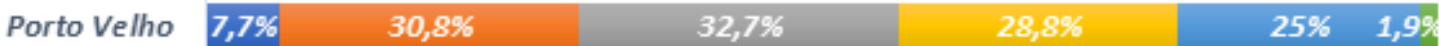

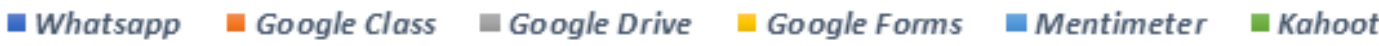

Os dados do Gráfico 15 mostram quais as ferramentas que tiveram mais dificuldades na utilização durante a formação remota em Porto Velho, sendo que em 10 lugar com 32,7\% foi o Google Drive (17), em 20 lugar o Google Classroom (16) com 30,8\%, em 30 lugar com 28,8\% ficou Google Forms (15), em 40 lugar com 3,2\% Mentimeter (13), em 50 lugar com 7,7\% o Whatsapp (4) e em 60 lugar com $1,9 \%$ o Zoom(1) e 1,9 \% relatou que teve problemas com a internet e 1,9\% afirmou não ter tido nenhuma dificuldade.

Quando indagados sobre as ferramentas que apresentaram mais dificuldades durante a formação em Candeias do Jamari, 59,5\% (47) responderam ser o Google Classroom; 16,5\% (13) Google Drive; empatados com 13,9\% (11) cada, Whatsapp e o Mentimeter; com 8,9\% (7), o Google Forms; um (1) professor respondeu que não teve nenhuma dificuldade, e outro respondeu ter dificuldade em todas.

Ao serem indagados sobre quais dificuldades que sentiram durante o processo formativo, $47,1 \%$ teve dificuldade com o domínio das ferramentas (24), 43,1\% em relação à incompatibilidade de horários, $29,4 \%$ dificuldade de acesso a equipamentos (15), o que pode demonstrar falta de recursos materiais e $25,5 \%$ afirmaram ser a dificuldade de acesso à internet (13). 


\section{Gráfico 16}

Quais as dificuldades você sentiu durante o processo formativo? Pode marcar mais de uma opção.

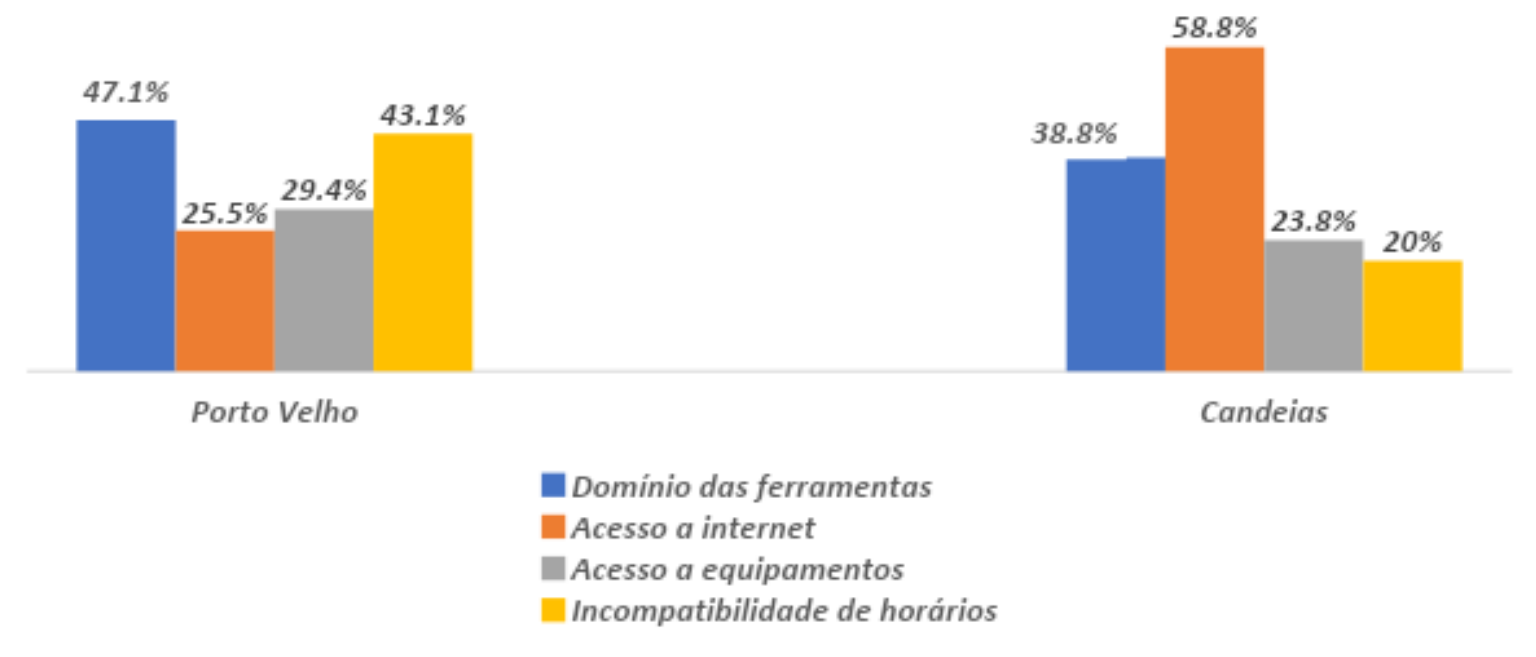

Em Candeias do Jamari, os pesquisados responderam que 47 deles, 58,8\% sentiram maior dificuldade quanto ao acesso à internet (conexão); 31, 38,8\% quanto ao domínio das ferramentas; 19 pesquisados, ou seja, 23,8\% dificuldades com o acesso a equipamentos; e 16, $20 \%$ incompatibilidade com horário.

\section{Gráfico 17}

\section{O tempo de formação foi suficiente?}

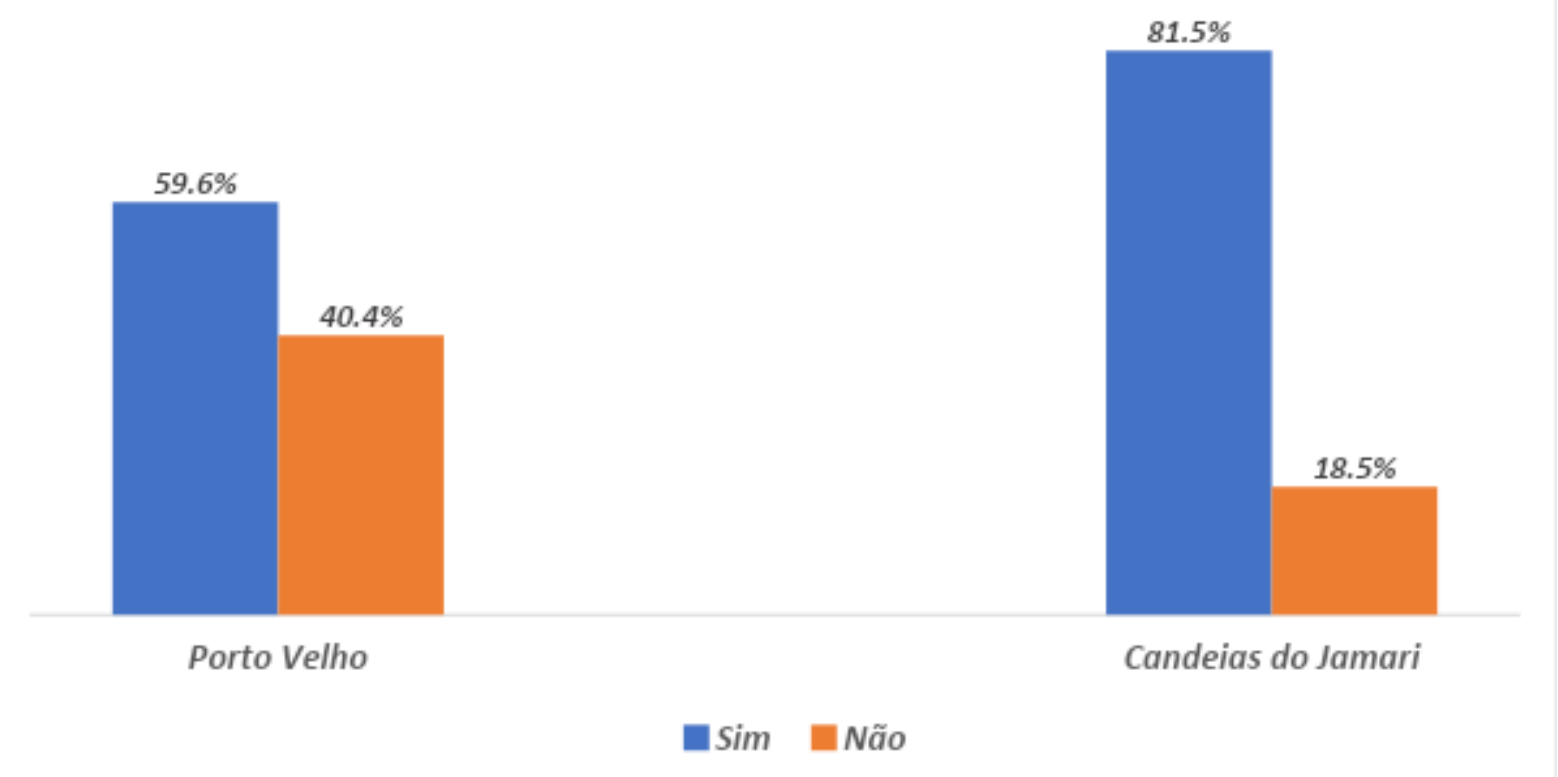

O Gráfico 17 confirma os resultados anteriores, que em Porto Velho 59,6\% dos professores afirmaram que o tempo de formação foi suficiente (31) e 40,4\% que não foi suficiente (21), em Candeias do Jamari, $81,5 \%$ (66) responderam que o tempo foi suficiente e $18,5 \%$ (15) que não foi. 


\section{Gráfico 18 \\ Você gostaria de que fosse ofertado mais horas de formação do RCRO?}

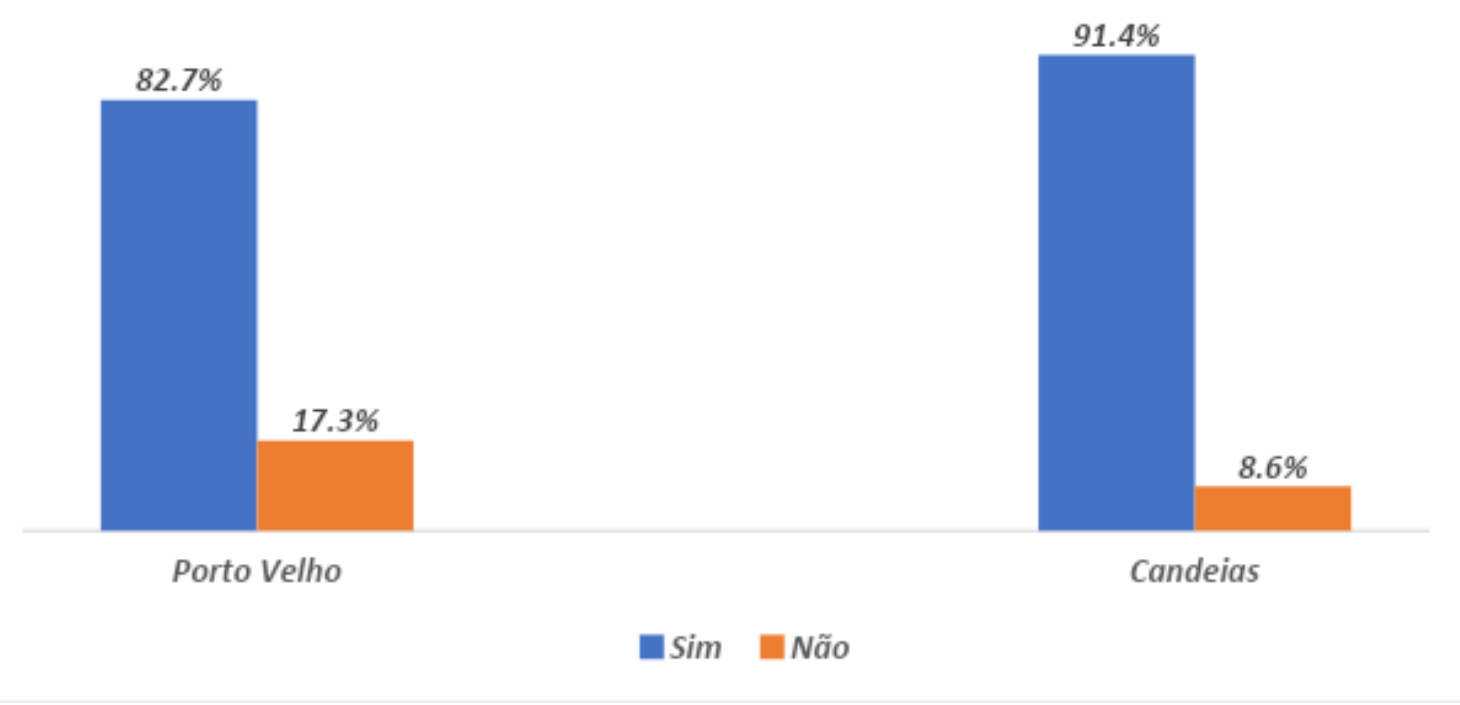

Neste Gráfico 18 mostra que em Porto Velho 82,7\% gostariam que fosse ofertado outros momentos formativos do RCRO (43), sugerindo que poderia haver acréscimo de horas complementares, abordando as temáticas de planejamento e avaliação no Componente de Educação Física e 17,3\% afirmam não ser necessário (9). Já em Candeias, 91,4\% dos professores pesquisados gostariam que houvesse mais horas de formação.

\section{CONSIDERAÇÕES GERAIS}

De forma concreta, neste e deste tempo e lugar fazemos as primeiras reflexões das considerações gerais, refletindo inicialmente que realizar formação continuada em níveis diferentes em processo contínuo e realizar esta pesquisa perpassou por uma caminhada de grandes desafios.

O primeiro foi o de acreditar que a pandemia era uma realidade em proporções sem medidas, daí conviver com isso foi um processo de medo, defesa, prevenção e, especialmente, de incertezas, um exercício de resiliência e de aprendizagem em todos os sentidos. $O$ segundo foi a necessidade de mudança no formato e estratégia metodológica da formação continuada, em situação de distanciamento social, portanto passaria para um modo ainda não imaginado e não vivenciado. $\mathrm{O}$ terceiro, ou seja, a equipe de formadores que já vinha executando formação presencial teve que, de modo autodidata, ressignificar-se, replanejar, adaptar meios e estratégias para a utilização de plataformas e ferramentas das quais, até então, não detinham o total domínio e nem faziam uso. 0 quarto foi garantir a realização da formação continuada com o uso de recursos virtuais para professores multiplicadores representantes de praticamente todos os municípios de Rondônia, em uma rede de comunicação coordenada a partir de Porto Velho.

Cabe neste ponto, destacar que de acordo com o objeto de estudo, o problema de pesquisa que norteou o estabelecimento dos objetivos, perpassa pelos seguintes aspectos: Em que medida a formação continuada virtual influenciou no pensamento e ação dos professores? Já o objetivo geral "analisar o contexto da formação continuada virtual de multiplicadores e de professores dos anos 
iniciais dos municípios de Rondônia e seus impactos e desafios em tempos de Covid-19", permite tecer algumas considerações.

Em relação ao contexto da formação continuada virtual de multiplicadores do RCRO dos municípios de Rondônia, é possível considerar que, apesar de todos os entraves, a formação realizada para os professores multiplicadores teve êxito, tendo em vista a qualidade das formações ministradas e pelos resultados obtidos nos questionários aplicados pelas formadoras.

A análise dos impactos gerados no processo da formação presencial para o processo de formação online (remota), em primeiro lugar, foi lidar com o impacto da pandemia e com as perspectivas de ter que ressignificar todo o processo de formação, sem perder de vista os conteúdos e a qualidade da formação de modo que não prejudicasse o ano letivo em percurso. Não se poderia deixar de relatar também os impactos financeiros, pois os professores tiveram que se adequar, tanto com equipamentos, como com instalação de internet de boa qualidade. $E$, também os impactos socioemocionais que, sem dúvida, acometeu-os seja por inseguranças no novo formato de aprender e ensinar, bem como lidar com as incertezas do futuro.

Nesse contexto, as dificuldades foram: falta de conhecimento das metodologias relacionadas aos recursos tecnológicos; materiais e equipamentos inadequados; professores sem condições financeiras para se adequarem. Assim, os resultados obtidos, com o suporte ilustrativo do gráfico abaixo e o que foi possível identificar em relação às mudanças no modo de pensar e agir dos multiplicadores e professores.

\section{Gráfico 19}

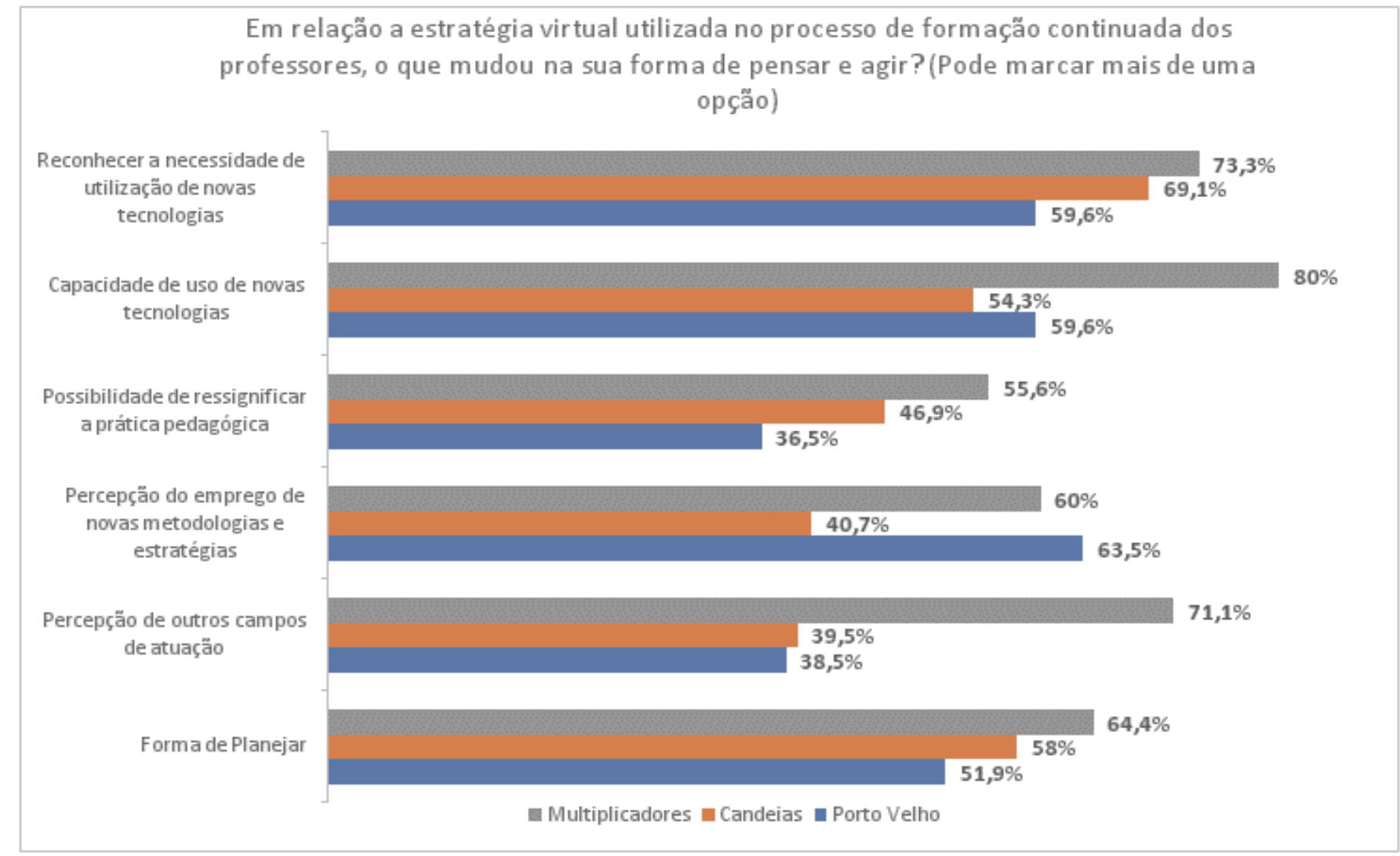

Ao serem levados a se autoavaliarem - o que mudou no seu modo de pensar e agir -, os dados indicaram que $\mathbf{8 0} \%$ apontaram que foi "a capacidade de uso de novas tecnologias". Isso se torna relevante como indicativo de aprendizado que fez diferença na vida profissional. 
O segundo indicador é "provocou mudança em seu modo e sua forma de pensar e agir", com 73,3\% reconhecendo "a necessidade do uso das tecnologias na educação". O terceiro indicador, com 71,1\% foi para "A percepção de outros campos de formação". O quarto indicador foi "a forma de planejar", apontada por $\mathbf{6 4 , 4 \%}$ dos participantes.

Em uma escala decrescente de percentuais, o quinto indicador apontado como fator de mudança foi "A percepção do emprego de novas tecnologias na educação" estando assim relacionado com o segundo indicador, foi apontado por $\mathbf{6 0 \%}$ dos respondentes e por fim o sexto indicador foi "a possibilidade de ressignificar a prática" indicado por $\mathbf{5 5 , 6 \%}$ dos multiplicadores.

Por se tratar de segmentos distintos, multiplicadores e professores - estes constituídos por dois grupos distintos -, as considerações indicadas como por três olhares, estarão direcionadas para o segundo e terceiro olhar de modo comparativo entre os dois grupos de professores, de Porto Velho e de Candeias do Jamari.

De modo comparativo, 63,5\% dos professores de Porto Velho indicaram a possibilidade de

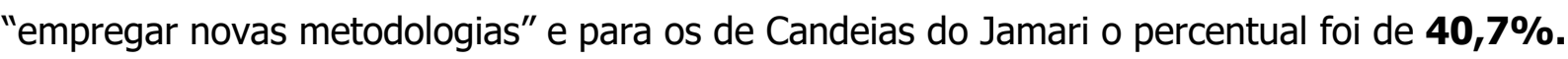

Para os de Porto Velho, com o mesmo percentual de 59,6,1\% indicaram "a capacidade de utilizar novas tecnologias" e "reconhecer a necessidade de utilizar novas tecnologias", por outro lado os de Candeias do Jamari, indicaram (respectivamente) percentuais diferentes, 54,3\%, e $69,1 \%$.

Com 51,9\% de indicações, os professores de Porto Velho disseram que "mudou a forma de planejar", e, de forma um pouco mais elevada, os de Candeias foi de $58 \%$;

Com dados bem próximos entre os dois municípios, para os professores de Porto velho o indicador "outros campos de formação "foi apontado por $\mathbf{3 8 , 5 \%}$ dos respondentes e para os professores de Candeias do Jamari o percentual foi de $\mathbf{3 9}, \mathbf{5 \%}$.

Em relação à "possibilidade de ressignificar a prática pedagógica" foi apontado por 36,5\% dos professores de Porto Velho e por $\mathbf{4 6 , 9 \%}$ dos professores de Candeias.

Em relação a esse foco de quanto a formação virtual provocou mudança no modo de pensar e agir, os índices percentuais dos multiplicadores, em cinco dos seis indicadores, foram acima dos professores dos dois municípios, porém no indicador "Percepção do emprego de novas tecnologias e estratégias", com $60 \%$ ficou entre os dois municípios, ou seja, abaixo de Porto Velho com 63,5\% e acima do Candeias do Jamari com 40,7\%.

Entre participantes e respondentes que manifestaram sobre essas mudanças estão os multiplicadores, 45 participantes e 45 respondentes; nos segmentos dos professores de Porto Velho foram 91, destes, 16 técnicos administrativos de apoio, perfazendo, assim, 75 professores e destes 52 responderam ao questionário, e do Candeias do Jamari foram 89 participantes e 79 respondentes, perfazendo respectivamente um total de 209 professores participantes das formações e destes 176 responderam à pesquisa, o que corresponde a 84\%, o que pode ser considerado um percentual elevado, e ainda, se considerar que essa questão ofereceu a opção "marcar mais de uma opção", todos os pesquisados marcaram em média 3 indicadores diferentes, cada um, a soma corresponde a 528 respostas, demonstrando a legitimidade desses dados, bem como os ganhos da formação continuada remota, em meio a uma pandemia mundial e local. 
Assim, diante dessas perspectivas da necessidade de mudanças e, como elas devem ou podem acontecer, recorremos a uma reflexão sobre "Mudando o modo de mudar" a partir de um editorial do Jornal Brasil Seikyo (2006), época em que a globalização impunha mudanças no modo de pensar e agir da população, tanto global quanto local, podendo ser, nas devidas proporções, pertinentes para esse momento, não só em tempos de pandemia, mas para o enfrentamento do pós-pandemia.

Mudar, mudanças, significam partir do pessoal para o social, uma grande transformação na atitude ou no modo de pensar, causando mudança com reflexos em seus ambientes. No editorial, destacamos que "quando nosso modo de pensar fundamental muda, nós próprios mudamos, e que quando isso acontece, o ambiente e o mundo também mudam". Essa pode ser a expectativa que se vislumbra no pós-pandemia, ressignificar as práticas.

No editorial menciona o destaca que:

\begin{abstract}
... em uma análise mais atenta, qualquer mudança inicia-se sempre com uma mudança de postura ou de atitude... E qualquer mudança de atitude, por sua vez, inicia-se com uma mudança no modo de pensar... quem deseja ... precisa, primeiro, convencer-se de que isso é necessário e importante. Nesse sentido, o comprometimento para com essa mudança é de importância suprema: sem um mínimo de comprometimento, com certeza não haverá mudança....
\end{abstract}

Esses poderão ser caminhos a serem trilhados pela escola e pela sociedade, partindo do individual ao coletivo, como forma de encarar a vida, pautada na reflexão e na conscientização de cada um, como desafios que virão pela frente, o que se espera é que as formações tenham contribuído de forma positiva, para provocar e promover mudanças no modo de pensar e agir dos professores em tempos de Covid-19.

Por fim, encerradas as formações, concluída a pesquisa, a equipe de pesquisadores agradece o apoio das instituições, às quais são vinculados: SEDUC Rondônia; SEMED de Porto Velho e Candeias do Jamari; Universidade Federal de Rondônia; às parcerias que asseguraram a realização do processo formativo - União Nacional dos Dirigentes Municipais de Educação - UNDIME e do Conselho Nacional de Secretários de Educação - CONSED e, em especial, o duplo agradecimento aos professores pela participação nas formações e pela contribuição na realização da pesquisa.

\title{
12. REFERÊNCIAS
}

ASSIS, Maria Cristina de. Metodologia do trabalho científico. In: FARIA Evangelina Maria B. de; ALDRIGUE, Ana Cristina S. (Orgs.). Linguagens: usos e reflexões. João Pessoa: Universitária/UFPB, 2008, v. II.

BERGMANN, B. Sala de aula invertida: uma metodologia ativa de aprendizagem / Jonathan Bergmann; Aaron Sams; tradução Afonso Celso da Cunha Serra. 1. ed. Rio de Janeiro: LTC, 2018.

BRASIL. Ministério da Educação. Secretaria de Ensino Fundamental. Programa de Formação de Professores Alfabetizadores - Guia de Orientações Metodológicas.

BOND, Aron. Diferença entre o aprendizado online e o ensino remoto de emergência. Revista da Escola, Professor, Educação e Tecnologia. Este artigo foi publicado originalmente no EDUCAUSE Review em 27 de Março de 2020. Traduzido por Danilo Aguiar, Dr. Américo N. Amorim e Dra. Lídia Cerqueira, com a permissão dos autores. Revista da Escola, Professor, Educação e Tecnologia v. 22020 escribo.com/revista. 
BORGES, Célio José. Formação e profissionalização de professores leigos em Rondônia: um estudo de caso - O PROHACAP (Programa de Habilitação e Capacitação de Professores) - Araraquara (SP): FCL., 2011. Tese (Doutorado).

CHANTRAINE-DEMAILLY, Lise. Modelos de formação contínua e estratégias de mudança. In Novoa, Antônio (org). Os professores e a sua formação. Lisboa: Dom Quixote, 1997.

CRESPO, N. D. O. et al. Ferramentas Digitais para o Ensino - O ensino remoto em evidência. Recife: Even3 Publicações, 20201. Livro digital; 85 p. il.ISBN: 978-65-88243-44-2

FADEL, L.M. et al. Gamificação na educação. São Paulo: Pimenta Cultural, 2014. 300p ISBN: 97885-66832-13-6.

FILATRO, Andrea. Como preparar conteúdo para EAD. 1. ed.- São Paulo: Saraiva, 2018.

FREITAS, M. I. C. de; CABRAL, M. P. The mapping in the continuing education of teachers: an experience through distance learning. In: International Technology, Education and Development Conference. Valencia, Espanha, 2011, v. 1. p. 1263-1268. Gerais. Brasília: MEC/SEF, 2001

GARCIA, Carlos Marcelo. A formação de professores: novas perspectivas baseadas na investigação sobre o pensamento do professor. In: NÓVOA, Antonio (org.). Os professores e a sua formação. Lisboa, Portugal: Dom Quixote, 1997.

GOOGLE. In: WIKIPÉDIA, a enciclopédia livre. Flórida: Wikimedia Foundation, 2020. Disponível em:<https://pt.wikipedia.org/w/index.php?title=Google\&oldid=59409662>. Acesso: 21 set. 2020.

HODGES, Charles, MOORE, Stephanie, LOCKEE, Barb, TRUST, Torrey e HODGES, Charles, MOORE, Stephanie, LOCKEE, Barb, TRUST, Torrey e LIBÂNEO, J. C. Didática. 22a. ed. São Paulo: Cortez, 2004.

INBERNON, Francisco. Formação Docente e profissional: formar-se para a mudança e a incerteza. 6. ed. São Paulo, Cortez, 2016.

JORNAL BRASIL SEIKYO. Edição 1843 - 13/05/2006 - p. A2 - Editorial.

LEVY, Steven. Google a biografia. São Paulo: Universo dos Livros, 2012.

MORAN, José M.; MASETTO, Marcos T.; BEHRENS, Marilda A. Novas tecnologias e mediação pedagógica. 3. ed. Campinas (SP): Papirus, 2000.

PACHECO, José Augusto Brito. O Pensamento e a Acção do Professor. Porto, Portugal: Porto, 1995.

PLACCO, Vera Maria. Nigro. Souza; SOUZA, Vera Lucia Trevisa (Orgs.). Aprendizagem do adulto professor. São Paulo: Loyola, 2006.

REVISTA SGI Quarterly. 0 mundo em 2030. Número 82. São Paulo, BSGI, 2015.

SANTANA, Lucas - Ensino remoto: Como aproveitar as ferramentas Google e outros recursos digitais. Disponível em: https://novaescola.org.br/conteudo/19799/ensino-remoto-como-aproveitar as-ferramentas-google-e-outros-recursos-digitais, Acesso:15/10/2020.

SILVA, Marijâne Silveira et al. Múltiplos olhares sobre a formação de professores no Brasil. Rondônia. Edufro. 2020). 